\section{Are Maternal Factors Predictors for Early Childhood Caries? Results from a Cohort in Southern Brazil}

\begin{abstract}
Gabriela dos Santos Pinto ${ }^{1}$, Marina Sousa Azevedo ${ }^{1}$, Marília Leão Goettems ${ }^{1}$,
\end{abstract} Marcos Britto Correa ${ }^{1}$, Ricardo Tavares Pinheiro ${ }^{2}$, Flávio Fernando Demarco ${ }^{1}$
1 Graduate Program in Dentistry, UFPel - Universidade Federal de Pelotas, Pelotas, RS, Brazil 2Graduate Program in Health in Behavior - UCPel - Universidade Católica de Pelotas, Pelotas, RS, Brazil

Correspondence: Flávio Fernando Demarco. R. Gonçalves Chaves, 457, $5^{\circ}$ and., 96015-560 Pelotas, RS, Brasil. Tel.: +55-53-3225-6741. e-mail: ffdemarco@gmail.com

Key Words: dental caries, preventive dentistry,

child, cohort study.

\begin{abstract}
This study aimed to determine the influence of maternal factors on the early development of dental caries in Brazilian preschoolers. This cross-sectional study was nested in a cohort of adolescent mothers. The current wave was performed when the children were aged 24 to 42 months. The questionnaire-based survey targeted adolescent mothers and included demographic and socioeconomic variables as well as the maternal education level. In addition, clinical examinations were performed on the mothers and their children. Mothers were assessed for decayed, missing and filled teeth in the permanent dentition (DMFT index) and gingival assessment; their children were assessed for decayed, missing and filled teeth in the deciduous dentition ( $\mathrm{dmft}$ index). Poisson regression with robust variance was used to estimate the prevalence ratio, risk ratio and 95\% confidence intervals. This data was also used to identify the maternal risk factors associated with the outcomes (prevalence and severity of childhood caries). A total 538 mother-child dyads were evaluated; the prevalence of early childhood caries was $15.1 \%$ and maternal caries was $74.4 \%$. After the adjustment, the children that exhibited a greater incidence of dental caries were from mothers of low socioeconomic status, or from those presenting decayed teeth and higher rates of gingival bleeding. The results of this study suggest that the oral health of mothers is a potentially important risk factor for the development of early childhood dental caries. Public health planners should consider this information when planning interventions in order to prevent the occurrence of early dental caries.
\end{abstract}

\section{Introduction}

Current evidence suggests that social structure, cultural, economic, environmental and health-system-related determinants are intrinsic factors involved in the etiology of dental caries. Therefore, non-biological determinants play an important role in dental caries $(1,2)$. In early childhood, the family acts as a mediator between a child and society, providing the necessary care and stimuli for growth and development. Regardless of its structure, the family represents the basic relational medium for the child's interactions with the world (3) and adequate care in the home environment depends on the availability of resources like the caregiver's schooling and knowledge and physical and mental health, time, autonomy, social support and financial resources (3).

Usually, the mother is the main caregiver during early childhood and plays a pivotal role in her child's health (4). Parents are the primary sculptors for behavior; the adoption of consistent childhood behavioral habits occurs at home with the parents, especially the mother (5). Furthermore, there are several well-supported pathways through which a mother's oral health status and its determinants directly influence her child's oral health. Indeed, there is a correlation between the mother's attitude toward oral health and dental care and the level of oral health and the degree of dental care utilization by the child (6). Some authors have also found that maternal oral health has an influence on the occurrence of early childhood caries (5). Mothers who have experienced extensive past or current caries may have need for counseling on the prevention of childhood caries (7). On the other hand, the adolescent mother/child relationship provides environmental changes since it results in less interaction between mother and child, less sensitivity for the needs of the baby, little stimulus to development and weak bonding (8). Children born from mothers younger than 23 years had the highest prevalence of caries and decayed, missing, or filled teeth (dmft) (9). It may be assumed that younger mothers are inexperienced in caring for their children or dealing with difficult children (9).

The literature has emphasized the need for studies beginning from the earliest possible age in order to provide information regarding the promotion of infant oral health, and the identification of infants and toddlers who are at risk for the development of childhood caries. This target population may benefit from specific and costeffective preventive measures, especially in disadvantaged communities (10). According to the Global Burden of 
Oral Disease, untreated caries in primary teeth is highly prevalent, affecting $9 \%$ of the world population (11). Dental caries in primary teeth is the main cause of dental pain in childhood. Caries and pain provoke dental fear, leading to the avoidance of dental treatment and consequently poor oral health, which can negatively influence the quality of life in children and parents (12).

Therefore, this study aimed to determine the influence of the maternal-related factors of young mothers on the early childhood caries of their offspring. Specifically, the study sought to determine whether maternal factors (educational level, living with a partner, occupation, family income and oral health conditions) could predict the occurrence of dental caries in their children.

\section{Material and Methods}

\section{Study Design and Population}

This cross-sectional study was conducted in Pelotas, southern Brazil and was nested in a cohort of pregnant adolescent women. Individuals were recruited from the public health care system (Brazilian National Unified Health System - SUS). During the prenatal visits, pregnant women aged 11 to 19 years, from the 47 basic health care units and 3 outpatient centers, comprising 95\% of the follow-up provided by SUS, were invited to participate in the study.

The enrolment of study participants occurred between October 2009 and March 2011. The sample size was calculated based on the aim of a major study: to detect the prevalence of mood disorders in the population of pregnant adolescents, and used the STATCALC tool of the Epi-Info software (Center for Diseases Control and Prevention, Atlanta, GA, USA). A sample size of 758 was needed in order to assess the prevalence of suicidal behavior estimated at $15 \%$ with a confidence level of $95 \%$, a power of $80 \%$ and an estimated risk of 1.55. Adding $15 \%$ to account for attrition, was attained a sample size of 871 participants. In 2012, when the children reached 2 years of age, clinical dental examinations of both mothers and children were conducted. From 871 mother-child dyads, the minimum sample size required for the detection of caries in children was 320 . This considered a relative risk of 2 , confidence level of $95 \%$, power of $80 \%$ and prevalence of dental caries at $63 \%$ in children aged 3 years with adolescent mothers (9). In order to account for attrition, 15\% was added to the sample, with 368 mother-child dyads required as the minimum sample size.

\section{Data Collection}

The fieldwork team was composed by 5 graduate students from the Federal University of Pelotas (UFPel) that acted as examiners and 5 undergraduate students with healthcare backgrounds that conducted the interviews.
The examiners and interviewers were trained and calibrated according to a previously described methodology (13). Inter-examiner reliabilities were calculated by weighted kappa test; the lowest value was 0.82 for dental caries in mothers and 0.85 in children.

When the children were aged 24-42 months, a new wave of the cohort was conducted, which consisted of a questionnaire for mothers and a clinical examination for both mothers and children.

The questionnaire collected information regarding personal data, socioeconomic profile, family income and the educational level of mothers. For maternal education, the number of years that participants attended school was considered and dichotomized into $\leq 8$ years (elementary school) and $>8$ years (high school or college). Family income was collected based on Brazilian minimum wages and divided into tertiles. The presence or absence of a parental partner and employment status were also among the considered factors.

Clinical examinations were performed using oral clinical mirrors, Community Periodontal Index (CPI) probes and sterile gauze. All biosecurity standards were rigorously followed. Children were seated on a chair facing away from the examiner and reclining to rest her or his head on the examiner's lap. Mothers were asked to sit comfortably on a chair and recline their head so that the oral cavity was clearly visible to the examiner.

Maternal gingival bleeding was assessed by running a periodontal probe along the cervical margins on 4 surfaces of 10 teeth $(17,16,11,26,27,37,36,31,46$ and 47$)$; the number of teeth with bleeding was determined and divided by the surface number. The sum was divided into tertiles; the first tertile was designated to lower gingival bleeding. The assessment of maternal caries was performed using different components of the DMFT index, each component was dichotomized (decayed, missing or filled) as yes or no. The presence of dental caries was dichotomized by yes (DMFT>0) or no.

In children, the number of decayed, missing/extracted and filled primary teeth (dmft) index was recorded according to the WHO criteria (14). Teeth lost as a result of trauma or exfoliation were excluded from the calculation. The prevalence of early childhood caries was defined when a child presented at least one decayed, extracted, or filled tooth due to caries $(\mathrm{dmft}>0)$. The $\mathrm{dmft}$ mean was used to determine disease severity.

\section{Statistical Methods}

The software STATA 12.0 (StataCorp, College Station, TX, USA) was used for the analyses. Associations between variables were tested by the chi-square test. In the multivariate analysis, Poisson regression with robust 
variance was used to estimate the prevalence ratio and 95\% confidence intervals (Cl) for the outcome of dental caries. For the outcome related to the severity of caries, risk ratio and $95 \% \mathrm{Cl}$ were determined. The analyses were performed to identify the maternal risk factors that may influence the occurrence and severity of dental caries in their children.

The selection of variables in the final model was performed using a backward stepwise method. To be included in the model, variables should present a $p$-value $\leq 0.25$.

\section{Ethics}

The study was approved by the Ethics in Research Committee of the Universidade Federal de Pelotas, protocol number 194/2011, following the Resolution 466/12 of the CNS or Statements of Helsinki declaration. The parents of each child provided written informed consent prior to inclusion in the study. Children and mothers diagnosed with caries were referred for treatment.

\section{Results}

The initial sample of adolescent pregnant women was 871; in this assessment, were evaluated 538 mother-child dyads, which represented $61.8 \%$ of the response rate. The maternal age ranged from 15 to 23 years with a median age of 20.20 years (SD 2.04). The age of the children ranged from 24 to 42 months (mean=29.9 months, SD 6.8). The prevalence of caries (DMFT>0) in mothers was $74.4 \%$, while $15.1 \%$ of their children had at least one decayed tooth ( $\mathrm{dmft}>0$ ).

The results of the bivariate analysis are shown in Table 1. The caries prevalence was greater in children born to mothers without a partner. Family income, maternal education level and maternal occupation were not associated with the prevalence of caries in children. Occurrence of maternal caries (DMFT $>0)$ presented a borderline association with the occurrence of caries in children. Mothers presenting decayed teeth had children with a higher degree of caries. The components $M$ (missing) and $F$ (filled) were not associated with the outcome. Mothers presenting higher gingival bleeding showed an association with the prevalence of caries in their children.

The results from the robust and adjusted multivariate Poisson regression analysis for the independent variables and the outcome are shown in Table 2. The unadjusted analysis of mothers living without a partner [PR=1.57 (95\% Cl: 1.05-2.35)], mothers presenting decayed teeth [PR=2.10 (95\% $\mathrm{Cl}: 1.33-3.33)]$ and mothers from the second $[\mathrm{PR}=2.34(95 \% \mathrm{Cl}: 1.33-4.13)]$ and highest
Table 1. Association between childhood caries experience and maternal and family socioeconomic status, demographic status and maternal and child oral health variables, in a sample of teenagers mothers in Pelotas, RS, Brazil. 2012

\begin{tabular}{|c|c|c|c|c|}
\hline \multirow{2}{*}{ Variable/Category } & \multicolumn{4}{|c|}{ Childhood caries experience $[\mathrm{dmfs}>0, \mathrm{n}(\%)]$} \\
\hline & Yes & No & Total & $\mathrm{p}$ value \\
\hline Total & $81(15.07)$ & 457 (84.93) & 538 & \\
\hline Maternal occupation & & & & 0.830 \\
\hline No & $53(15.41)$ & $291(84.59)$ & $344(63.59)$ & \\
\hline Yes & $29(14.72)$ & $168(85.28)$ & $197(36.41)$ & \\
\hline Living with a partner & & & & 0.027 \\
\hline Yes & $35(12.03)$ & $256(87.97)$ & $291(53.89)$ & \\
\hline No & $47(18.88)$ & $202(81.12)$ & $249(46.11)$ & \\
\hline Family income & & & & 0.107 \\
\hline $1^{\text {st }}$ tertile & $29(16.02)$ & $152(83.98)$ & $181(34.60)$ & \\
\hline $2^{\text {nd }}$ tertile & $30(17.54)$ & $141(82.06)$ & $171(32.70)$ & \\
\hline $3^{\text {rd }}$ tertile & $17(9.94)$ & $152(90.06)$ & $171(32.70)$ & \\
\hline Mother's education level (yrs) & & & & 0.346 \\
\hline$\leq 8$ & $42(16.54)$ & $212(83.46)$ & $254(47.04)$ & \\
\hline$>8$ & $39(13.64)$ & $247(86.36)$ & $286(52.96)$ & \\
\hline Mother's caries experience & & & & 0.056 \\
\hline $\mathrm{DMFT}>0$ & $68(16.79)$ & $337(83.21)$ & $405(74.45)$ & \\
\hline $\mathrm{DMFT}=0$ & $14(10.07)$ & $125(89.93)$ & $139(25.55)$ & \\
\hline Mother's Decayed Teeth & & & & 0.001 \\
\hline Yes & $60(19.54)$ & 247 (80.46) & $307(56.43)$ & \\
\hline No & $22(9.28)$ & 215 (90.72) & $237(43.57)$ & \\
\hline Mother's Missing Teeth & & & & 0.816 \\
\hline Yes & $25(15.63)$ & $135(84.38)$ & $160(29.41)$ & \\
\hline No & $57(14.84)$ & $327(85.16)$ & $384(70.59)$ & \\
\hline Mother's Filled Teeth & & & & 0.437 \\
\hline Yes & $48(16.16)$ & $249(83.84)$ & $297(54.60)$ & \\
\hline No & $34(13.77)$ & $213(86.23)$ & $247(45.40)$ & \\
\hline Mother's gingival bleeding & & & & 0.003 \\
\hline $1^{\text {st }}$ tertile & $16(8.12)$ & $181(91.88)$ & $197(36.21)$ & \\
\hline $2^{\text {nd }}$ tertile & $32(19.05)$ & $136(80.95)$ & $168(30.88)$ & \\
\hline $3^{\text {rd }}$ tertile & 34 (18.99) & 145 (81.01) & $179(36.90)$ & \\
\hline
\end{tabular}

Chi-square test. 
tertile of gingival bleeding [PR=2.34 (95\% $\mathrm{Cl}$ : 1.34-4.09)] showed a significant association with a higher prevalence of early childhood caries. After the adjustment for confounding variables, children born to mothers presenting decayed teeth $[\mathrm{PR}=1.79(95 \% \mathrm{Cl}: 1.11-2.90)]$, and those in the second [PR=2.10 (95\% Cl: 1.18-3.73)] and the highest tertile of gingival bleeding $[\mathrm{PR}=1.81(95 \% \mathrm{Cl}$ : 1.02-3.21)] presented greater prevalence of dental caries.

Table 3 shows factors related to the severity of caries after a multivariate analysis. In the crude analysis, family income, maternal caries and gingival bleeding were associated with higher dmft means in the children. After adjustments, children born to mothers presenting caries (DMFT>0) [RR=2.20 (95\% Cl: 2.05-4.66)] presented an increased severity of disease $(p=0.039)$. In addition, significant associations $(p=0.014)$ were found in the 3rd tertile of family income [RR 0.40 (95\% Cl: 0.19-0.84).

\section{Discussion}

The obtained findings demonstrated that the presence of decayed teeth in mothers was associated with the occurrence of caries in their children. This agrees with previous reports observing that mothers presenting high levels of untreated caries were more likely to have children with increased incidence of caries, regardless of poverty status (6).

The importance of maternal factors from young mothers on early childhood caries of their offspring should be considered in the development of oral health promotion programs. Mother's oral health was associated with childhood dental caries. This relationship may have operated by oral hygiene behaviors. Mothers failing to have self-care will not take care of their children's oral health.

The prevalence of caries in the preschool student sample was $15.1 \%$, corroborating previous study that described high rates of caries in the primary dentition of children under 5 years of age (15). In a survey of Brazilian 5-yearolds conducted in 2010,53.4\% of children had at least one decayed primary tooth (16). Currently, especially in developing countries, a significant proportion of infants and preschool aged children are affected by dental disease with a 
strong polarization; this includes Brazilian children (17). Furthermore, the prevalence of early childhood caries (ECC) is greatest among the most disadvantaged groups in society, specifically racial or ethnic minorities and the poor (18). In fact, in the present study mothers with lower familial income were also associated with higher disease severity in their offspring.

The overall results of this study showed a positive association between maternal oral clinical variables (decayed teeth and gingivitis) and the occurrence of caries in their children.

The relationship between mothers with high levels of gingivitis and their children with high rates of dental caries may be explained. Gingivitis (gingival bleeding) is used as an oral hygiene indicator; where there are higher levels of gingival bleeding, it may indicate poor oral hygiene habits in those individuals (19). Mothers are generally responsible

Table 3. Crude (c) and Adjusted (a) Prevalence Ratios (PR) for Maternal Independent Variables and Child Caries Severity in a sample of teenagers mothers in Pelotas, RS, Brazil, 2012

\begin{tabular}{|c|c|c|c|c|c|c|}
\hline \multirow{2}{*}{ Variable/Category } & \multicolumn{6}{|c|}{ Childhood caries severity [dmfs] } \\
\hline & RRC & $95 \% \mathrm{CI}$ & $\mathrm{p}$ value & RRA & $95 \% \mathrm{CI}$ & $\mathrm{p}$ value \\
\hline Maternal occupation & & & 0.541 & -- & & \\
\hline Yes & 1 & & & & & \\
\hline No & 1.21 & $0.65-2.25$ & & & & \\
\hline Living with a partner* & & & 0.213 & -- & & \\
\hline Yes & 1 & & & & & \\
\hline No & 1.43 & $0.81-2.50$ & & & & \\
\hline Family income* & & & 0.019 & & & 0.014 \\
\hline $1^{\text {st }}$ Tertile & 1 & & & 1 & & \\
\hline $2^{\text {nd }}$ Tertile & 1.17 & $0.62-2.22$ & & 1.08 & $0.58-2.06$ & \\
\hline $3^{\text {rd }}$ Tertile & 0.39 & $0.18-0.84$ & & 0.40 & $0.19-0.84$ & \\
\hline Mother's education level (yrs) & & & 0.540 & -- & & \\
\hline$>8$ & 1 & & & & & \\
\hline$\leq 8$ & 1.19 & $0.68-2.09$ & & & & \\
\hline DMFT & & & 0.006 & & & 0.039 \\
\hline No & 1 & & & 1 & & \\
\hline Yes & 2.53 & $1.31-4.88$ & & 2.20 & $2.05-4.66$ & \\
\hline Mother's gingival bleeding* & & & 0.001 & & & 0.121 \\
\hline $1^{\text {st }}$ Tertile & 1 & & & 1 & & \\
\hline $2^{\text {nd }}$ Tertile & 2.59 & $1.28-5.22$ & & 2.19 & $1.04-4.60$ & \\
\hline $3^{\text {rd }}$ Tertile & 2.58 & $1.25-5.32$ & & 1.90 & $0.83-4.38$ & \\
\hline
\end{tabular}

Variables that presented a P-value $\geq 0.25$ were not included in the final model after the adjustment; $\mathrm{PR}=$ Prevalence ratio; $\mathrm{CI}=$ Confidence interval; $\mathrm{C}=$ Crude analysis; $\mathrm{A}=$ Adjusted analysis for the implementation of oral health behaviors in their children. If mothers exhibit deficient habits, it is plausible that their children will also exhibit unfavorable oral health habits and consequently, a higher level of dental caries may be expected (12). In addition, negative oral health behavior in mothers may produce impairment in the oral health condition of children. This may lead them to avoid dental treatment. Furthermore, maternal patterns of dental attendance may be related to those adopted in their children. The avoidance of dental treatment by mothers creates a worse scenario for their children's oral health (20). Indeed, a recent study observed that maternal oral health practices from mothers were associated to children's caries prevalence and also that mothers could accurately evaluate their children's oral health (21).

In reference to socio-economical factors, children from mothers located in the higher tertile of family income had a decreased severity of dental caries (lower dfmt index). The relationship between socioeconomic factors and oral health status has been well established in the literature. Indeed, some studies have already shown an association between the lower socioeconomic status of mothers and the higher prevalence of caries in their children (22). The present study found a lack of association between maternal education and the occurrence of dental caries in children. Higher socioeconomic status was considered a protective factor; mothers with a greater socioeconomic standing had children with a decreased occurrence of dental caries. It is important to highlight some important details in relation to the study sample. All mothers had a similar age (adolescent), presented similar educational experience, and since they utilized the Public Health System for prenatal care, they shared similar low socioeconomic backgrounds. In addition, it is important to emphasize that this cohort was composed of adolescent women; therefore, they were less likely to have many years of education. In fact, few had the potential to complete high school or attend college at university level. Therefore, the similarities in relation to low socioeconomic backgrounds 
and lower education levels among the mothers may make it difficult to detect the influence of these variables in the prevalence of caries in their children. Mothers from high socioeconomic levels treated in private practice were not included, meaning that the cohort was not a populationbased study. However, in this low socioeconomic sample, the mothers from the wealthier tertile had a decreased likelihood of presenting offspring with a high level of caries. Children from low socioeconomic status are likely to have more ECC at the preschool age (24).

The similarity of low socioeconomic status in this sample of adolescent mothers may be considered a limitation of this study, since it could impair the observation of potential associations. Another limitation of this study was the use of cross-sectional data, which is difficult for the establishment of temporal relationships. Important strengths of the present study were the elegant methodological design, the appropriate statistical analysis and the large sample size of mother-child dyads, which ensured the power of the obtained data.

Public health strategies should emphasize that each child receives dental care prior to the age of one year in order to implement preventive measures and target parents for educational programs. Furthermore, it is now recommended that all women receive a comprehensive oral health evaluation from prenatal care practitioners during pregnancy and be referred for appropriate dental treatment. These recommendations will aid in the management of significant bacterial and inflammatory conditions, improve oral health and function, and reduce the risk of ECC (25).

In conclusion, this study has shown an association between the oral health of mothers and the occurrence of dental caries in their children. This relationship may have been facilitated by oral hygiene behaviors. The results modestly support the hypothesis that mothers who do not practice self-care will not engage in the oral health care of their children. Findings of this study suggest that the oral health of mothers is potentially an important risk factor for childhood dental caries; these results should be considered for the development of programs that promote oral health.

\section{Resumo}

Objetivo deste estudo foi determinar a influência de fatores maternos sobre o desenvolvimento de cárie em pré-escolares brasileiros. Este estudo transversal foi aninhado em uma coorte de mães adolescentes. Esta fase foi realizada quando as crianças estavam com idades entre 24 a 42 meses. 0 questionário aplicado às mães adolescentes incluiu variáveis demográficas, socioeconômicas e a escolaridade materna. Os exames clínicos foram realizados nas mães e em seus filhos. 0 exame clínico das mães avaliou dentes cariados, perdidos e restaurados na dentição permanente (CPOD) e condição gengival; o exame clínico dos filhos avaliou dentes cariados, perdidos e restaurados na dentição decídua (ceo-d). Regressão de Poisson com variância robusta foi utilizada para estimar a razão de prevalência, risco relativo e os intervalos de confiança de 95\%. Os dados também foram utilizados para identificar os fatores de risco maternos associados com o desfecho (prevalência e severidade da cárie na infância). No total, foram avaliados 538 diades mãe-criança; a prevalência de cárie precoce na infância foi de 15,1\% e a cárie materna ocorreu em $74,4 \%$. Após ajuste, as crianças que apresentaram uma maior incidência de cárie dentária eram filhas de mães de baixo nivel socioeconômico, que apresentam mais dentes cariados e mais sangramento gengival. Os resultados deste estudo sugerem que a saúde bucal das mães é um fator de risco potencialmente importante para o desenvolvimento da cárie da primeira infância. Gestores de saúde pública devem considerar esta informação ao planejar intervenções, a fim de prevenir a ocorrência de cárie da primeira infância.

\section{Acknowledgments}

The authors would like to thank the State Funding Agency (FAPERGS) for the grant (\#11/1189-4) that allowed this study to be performed, given to the PI (FFD). Also, we would like to thank FAPERGS for the scholarship given to the first author (GSP). The authors are grateful to the graduate and undergraduate students that participated in the fieldwork. We would like to thank the Catholic University of Pelotas staff for their collaboration as well as the Post-Graduate Program in Health in Behavior for the assistance. Finally, we would like to honor the Professor Dione Dias Torriani (In memorian) for her commitment and dedication to this project.

\section{References}

1. Frazão P. Epidemiology of dental caries: when structure and context matter. Brazil Oral Res 2012;26:108-114.

2. Congiu G, Campus G, Lugliè PF. Early childhood caries (ECC) prevalence and background factors: a review. Oral Health Prev Dent 2014;12:7176.

3. Almeida TF, Vianna MIP. Family context and preschool children's oral health: a quali-quantitative approach in Salvador, State of Bahia, Brazil. Rev Ciênc Med Biol 2013;12:5-14.

4. Andrade MRTC, Canabarro A, Moliterno LF. Experience of dental caries in mother/child pairs: association between risk indicators and dental caries. Rev Gaúcha Odontol 2012;60:179-185.

5. Agarwal V, Nagarajappa R, Keshavappasb, Lingesha RT. Association of maternal risk factors with early childhood caries in schoolchildren of Moradabad, India. Int J Paediatr Dent 2011;21:382-388.

6. Dye BA, Vargas CM, Lee JJ, Magder L, Tinanoff N. Assessing the relationship between children's oral health status and that of their mothers. J Am Dent Assoc 2011;142:173-183.

7. Zanata RL, Navarro MF, Pereira JC, Franco EB, Lauris JR, Barbosa SH. Effect of caries preventive measures directed to expectant mothers on caries experience in their children. Braz Dent J 2003;14:75-81.

8. Bromwich R. Adolescent parents and parenting. Working with families and their infants at risk: a perspective after 20 years of experience. Austin Texas: Pro-ED 1997;289-292.

9. Niji R, Arita $K$, Abe $Y$, Lucas ME, Nishino M, Mitome M. Maternal age at birth and other risk factors in early childhood caries. Pediatr Dent 2010;32:493-498.

10. Ismail Al. Determinants of health in children and the problem of Early Childhood Caries. Pediatr Dent 2003;25:328-332.

11. Marcenes W, Kassebaum NJ, Bernabé $E$, Flaxman A, Naghavi M, Lopez A, et al.. Global burden of oral conditions in 1990-2010: a systematic analysis. J Dent Res 2013;92:592-597.

12. Boeira GF, Correa MB, Peres KG, Peres MA, Santos IS, Matijasevich A, et al.. Caries is the main cause for dental pain in childhood: findings from a birth cohort. Caries Res 2012;46:488-495.

13. Goettems ML, Correa MB, Vargas-Ferreira F, Torriani DD, Marques $M$, Domingues MR, et al.. Methods and logistics of a multidisciplinary survey of schoolchildren from Pelotas, in the Southern Region of Brazil. Cad Saude Publica 2013;29:867-878.

14. World Health Organization/FDI (1997). Oral health surveys: basic methods.4th ed. Geneva, Switzerland: WHO.

15. Wong HM, McGrath CPJ, King NM, Lo ECM. Oral health related quality of life in Hong Kong preschool children. Caries Res 2011;45:370-376.

16. Ministério da Saúde. Secretaria de Atenção à Saúde. Secretaria de 
Vigilância em Saúde. SB Brasil 2010: Pesquisa Nacional de Saúde Bucal: resultados principais / Ministério da Saúde. Secretaria de Atenção à Saúde. Secretaria de Vigilância em Saúde. - Brasilia : Ministério da Saúde, 2012.

17. Rosenblatt $A$, Zarzar P. The prevalence of early childhood caries in 12- to 36-month-old children in Recife, Brazil. ASDC J Dent Child 2002;69:319-324.

18. Dye BA, Tan S, Smith V, Smith V, Lewis BG, Barker L, et al.. Trends in oral health status: United States, 1988-1994 and 1999-2004. Vital Health Stat 11 2007;248:1-92.

19. Nascimento GG, Seerig LM, Vargas-Ferreira F, Correa FO, Leite FR, Demarco FF. Are obesity and overweight associated with gingivitis occurrence in Brazilian schoolchildren? J Clin Periodontol 2013;40:1072-1078.

20. Goettems ML, Ardenghi TM, Demarco FF, Romano AR, Torriani DD. Children's use of dental services: influence of maternal dental anxiety, attendance pattern, and perception of children's quality of life. Community Dent Oral Epidemiol 2012;40:451-458.

21. Pinto GS, Hartwig AD, Elias R, Azevedo MS, Goettems ML, Correa MB, et al.. Maternal care influence on children's caries prevalence in southern
Brazil. Braz Oral Res 2016 31;30:e70.

22. Santos Junior V, Sousa RM, Oliveira MC, Caldas Junior AF, Rosenblatt A. Early childhood caries and its relationship with perinatal, socioeconomic and nutritional risks: a cross-sectional study. Oral Health 2014;6:47.

23. Ferreira SH, Béria JU, Kramer PF, Feldens EG, Feldens CA. Dental caries in 0- to 5-year-old Brazilian children: prevalence, severity and associated factors. Int J Paediatr Dent 2007;17:289-296.

24. Tinanoff $N$, Reisine S. Update on early childhood caries since the Surgeon General's Report. Acad Pediatr 2009;9:396-403.

25. George A, Shamim S, Johnson M, Dahlen H, Ajwani S, Bhole $S$, et al.. How do dental and prenatal care practitioners perceive dental care during pregnancy? Current evidence and implications. Birth 2012;39:238-247.
Received October 25, 2016 Accepted February 15, 2017 